Theoretical and Applied Climatology

(C) Springer-Verlag 1998

Printed in Austria

\title{
A Diagnostic Study of the Global Distribution of Contrails Part I: Present Day Climate*
}

\author{
R. Sausen, K. Gierens, M. Ponater, and U. Schumann
}

With 7 Figures

Received October 1, 1997

Revised July 10, 1998

\section{Summary}

The global distribution of contrail formation potential and contrail cloud coverage are estimated using meteorological analyses of temperature and humidity (ECMWF reanalyses) and an aircraft fuel inventory. A large potential for contrail formation is found in the upper troposphere, in particular in the tropics, but also at mid-latitudes. The global potential contrail coverage is calculated to be $16 \%$.

The actual contrail coverage is proportional to the product of the potential coverage and the fuel consumption of 1991/92 air traffic. The actual global contrail coverage is $0.09 \%$, however, the pattern of main air routes show up in the geographical distribution of contrail coverage with maximum values of more than $5 \%$. Regionally, contrail coverage shows a distinct annual cycle, with larger values in winter than in summer, in the mid-latitudes. The result is only weakly sensitive to the propulsion efficiency of aircraft, but strongly sensitive to aircraft flight altitude.

\section{Introduction}

Aircraft emissions can modify climate in several ways: (1) aircraft emit substances which are radiatively active (e.g., $\mathrm{CO}_{2}, \mathrm{H}_{2} \mathrm{O}$ ), (2) they emit substances which produce or destroy radiatively active substances (e.g., $\mathrm{NO}_{\mathrm{x}}$ which modifies the $\mathrm{O}_{3}$ concentration), (3) the emissions (e.g.,

\footnotetext{
* Dedicated to Prof. Dr. F. Wippermann on the occasion of his
} 75th birthday.
$\mathrm{H}_{2} \mathrm{O}$, soot) trigger the generation of additional clouds (contrails). Apart from noise, contrails are the most noticeable environmental impact of aircraft.

Studies of contrails go back as far as 1919. The first consistent theories for the conditions necessary for contrail formation were given by Schmidt (1941) and Appleman (1953). Recently, Schumann (1996) reviewed the present knowledge of contrail formation. According to the Schmidt-Appleman criterion, contrails occur when the ambient air temperature is cooler than some threshold value, which depends on the flight level, ambient humidity and aircraft propulsion efficiency. A typical value is $-40^{\circ} \mathrm{C}$. In addition to the criterion for contrail formation, persistence of contrails requires that the ambient air is frost-saturated, i.e. super-saturated with respect to the ice phase and not saturated with respect to the water phase. Such situations typically occur ahead of warm fronts in a cyclone or downstream of convective complexes. Persistent contrails are not basically formed from the water emitted by aircraft. Rather, the aircraft emissions trigger the formation of additional clouds from natural water vapour present in the atmosphere.

The climatic impact of contrails was addressed recently by several papers, and an overview is 
given by Brasseur et al. (1998). Strauss et al. (1998) estimated the local climatic effect in Southern Germany to be in the range of a few hundredth of a K. Ponater et al. (1996a) addressed the global climatic effect. With a rather simplified approach they demonstrated that contrails have the potential to induce significant climate changes. The magnitude of the effect strongly depends on the area fraction covered by contrails, as well as on their thickness.

Miake-Lye et al. (1993) determined the regions where at least short-lived contrails may form using climatological zonal mean fields of temperature and humidity. Observational contrail statistics on hemispheric scale for multi-year periods are not available at present. Several authors have estimated the observational frequency of the occurrence of contrails and the fraction of the sky covered by contrails, e.g. Minnis et al. (1997) report observations being made at 19 stations in the contiguous USA. The visual inspection of satellite images of Central Europe suggests that, on average, $0.4 \%$ of the area is covered by contrails, i.e. high clouds that are linear in shape (Schumann and Wendling, 1990). Similarly, Bakan et al. (1994) derived from seven years (September 1979-December 1981 and September 1989-August 1992) of NOAA/AVHRR infrared satellite images of the Eastern Atlantic/Western Europe an annual mean contrail coverage of about $0.5 \%$, with regional maxima in the North Atlantic flight corridor of more than 2\%. Recently, Mannstein et al. (1998) presented an objective routine for automatic detection of contrails. An application to NOAA/AVHRR data for Central Europe revealed a contrail coverage of at least $0.5 \%$. All these studies did not account for older contrails which have grown to such a large size that they are no longer linear in shape, nor for other "natural" clouds which have potentially been produced by aerosols emitted by aircraft earlier. Hence the numbers provided above should be regarded as lower limits of contrail coverage. In a flight experiment, NASA demonstrated that contrails can grow to a very large cirrus cloud (Minnis et al., 1998). If the history of this cirrus cloud was not known, it is likely that no-one would have characterised this cloud as aircraft generated.
In the present paper we diagnose the global contrail coverage from assimilated meteorological data. The method is based on a scheme used to parametrise high cloud coverage from temperature and humidity in a GCM. The SchmidtAppleman criterion is applied to determine contrail existence if there is air traffic. We use ECMWF re-analysis data (Gibson et al., 1997) for the meteorological information and the DLR-2 data set (Schmitt and Brunner, 1997) as a measure for the air traffic. In Section 2 we describe the two data sets. The method for diagnosing the contrails is presented in Section 3. Section 4 covers the results and their discussion. Finally, the conclusions are presented in Section 5.

\section{Data}

\subsection{ECWMF re-Analysis Data}

Numerical meteorological analyses are based on raw data, the density and quality of which varies with time: some data sources deliver only temporarily (e.g., due to political situations or due to different spatial patterns of reporting commercial ships), some finish (like weather ships) and some are newly introduced (like new satellite channels). Furthermore, the numerical forecasting model inherent in the data assimilation scheme is modified from time to time in order to include new concepts which enhance the forecast skill, however, this causes inhomogeneities in the analysis system and time series.

In order to overcome the latter inhomogeneity, two re-analysis projects have been launched: one at ECMWF (Gibson et al., 1997); and one at NCEP/NCAR (Kalnay et al., 1996). In each case the raw data have been re-analysed using an identical analysis scheme. We make use of the ECMWF re-analysis data (initialised data) for the present study. In the following, we consider the 11 years from 1983 to 1993 .

Upper level humidity has been a rather uncertain parameter in analyses for a long time. The ECMWF scheme has significantly improved in this aspect. For instance, Ovarlez and van Velthoven (1997) have shown a reasonable quality of the ECMWF humidity data by comparing it with in situ measurements in the upper troposphere over the Atlantic, west of Ireland. Also, comparison of DC-8 observations 
and UARS microwave sounder measurements with ECMWF re-analyses shows good agreement and demonstrates the ECMWF model's ability to reproduce the conditions necessary for cirrus clouds (Newell et al., 1996). Nevertheless, the humidity data are still not good enough for a reliable contrail analysis. In nature, supersaturation and cloud formation can be achieved locally whereas the grid mean value, which is representative for a rather large region, may still be below saturation. In the ECMWF scheme, like in many GCMs, this problem is solved by allowing cloud formation at humidities below saturation. In addition, the ECMWF scheme allows no humidity above ice saturation if the temperature is cold enough. Hence the initialised re-analysis data also suffer from the coarse resolution of grid point data. However, the humidity data are good enough to be used in a suitable cloud parametrisation scheme.

Temperature and specific humidity at $12 \mathrm{~h} \mathrm{UT}$ have been used here. Horizontally we have reduced the resolution to a Gaussian grid corresponding to a T42 spectral model, i.e. $\approx 2.8^{\circ} \times 2.8^{\circ}$. This resolution appears to be sufficient in view of the spatial uncertainties of the aircraft data (cf. Section 2.2). Vertically we use data that have been interpolated to the 150 , 200, 250, 300 and $400 \mathrm{hPa}$ levels. This includes the altitudes of the cruise flight levels.

\subsection{DLR-2 Air Traffic Data}

As there is no inventory of the present day air traffic density (number of flights per grid volume and time unit) currently available, we use an inventory of aircraft fuel consumption as a substitute. We use the DLR-2 aircraft emission inventory (Schmitt and Brunner, 1997). The basis of this data set is a combination of actually reported movements by air traffic control (ATC) and time table sources. The traffic data have been collected for four months (January, April, July and October) aggregated to a 1991/92 reference year. Aircraft/engine combinations are represented by generic aircraft in order to calculate the fuel consumption along the different flight routes. In this way Schmitt and Brunner (1997) assumed that city pairs are connected by great circle routes. The horizontal resolution of the aircraft fuel consumption inventory is given by a Gaussian grid corresponding to a T42 spectral model, i.e. $\approx 2.8^{\circ} \times 2.8^{\circ}$. The vertical resolution is $1 \mathrm{~km}$ (pressure altitude).

The annual mean fuel consumption above $500 \mathrm{hPa}$ is plotted in Fig. 1. The main flight routes such as the North Atlantic flight corridor or the route from Europe to South-East Asia are evident. Less frequently used routes like those from Europe to South America or from the continental USA to Hawaii can also be seen.

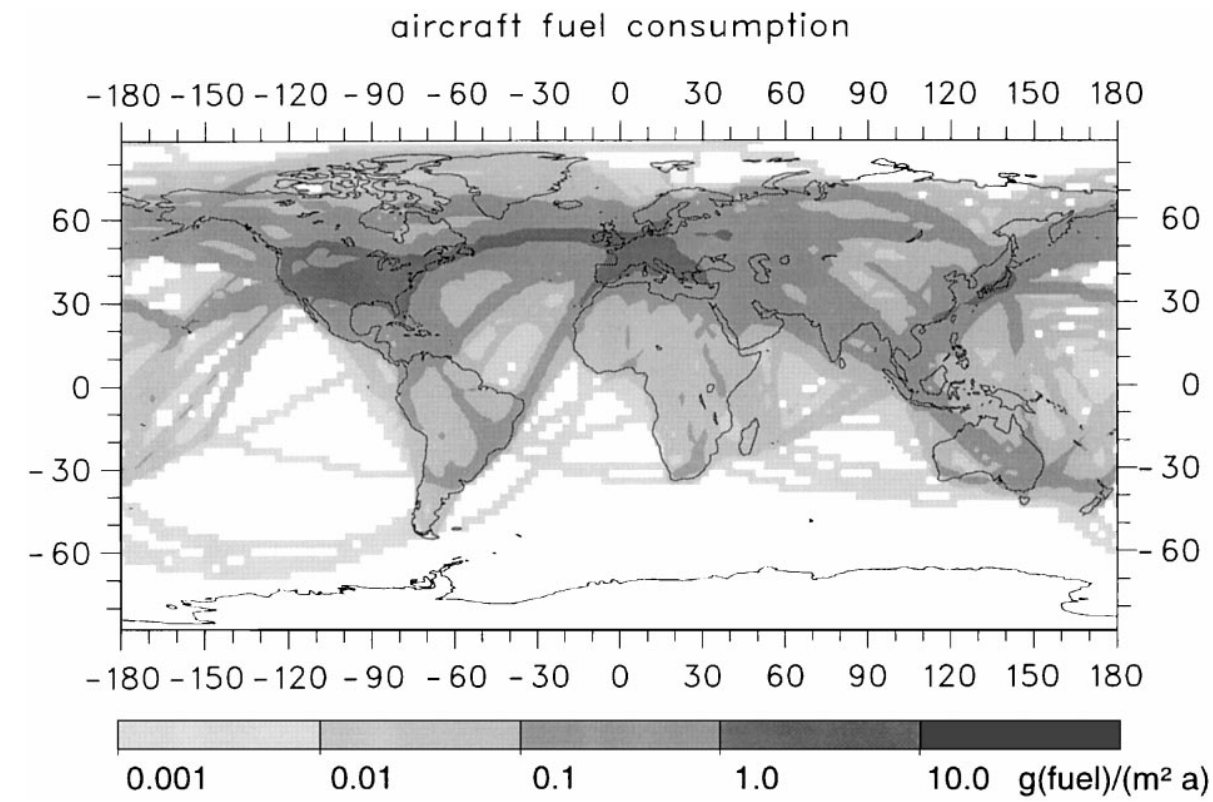

Fig. 1. Vertically integrated annual mean fuel consumption by aircraft $\left[\mathrm{g}(\right.$ fuel $\left.) /\left(\mathrm{m}^{2} \cdot \mathrm{a}\right)\right]$ above $500 \mathrm{hPa}$ according to the DLR2 data set (Schmitt and Brunner, 1997). Contour spacing varies logarithmically 
Note that logarithmic spacing is used between the plotted contours.

\section{Method}

Contrails can persist if the Schmidt-Appleman criterion is fulfilled and the ambient air is supersaturated with respect to ice but not with respect to water (cf. Gierens et al., 1997). In order to determine the regions of the globe where persistent contrails can exist we should therefore compute from the physical variables pressure $p$, temperature $T$, and relative humidity $U$, an indicator variable which has the value 1 when the above conditions are fulfilled, otherwise it would assigned the value zero. With such an indicator value defined the statistical evaluation of contrail frequency from the data sets would be quite straightforward.

Unfortunately we cannot follow this strategy, since the relative humidities in the re-analysis data are mainly model results in the upper troposphere (because of the lack of humidity data with sufficient quality in these altitudes) and they only very seldom exceed ice-saturation. This is an effect of the cloud scheme in the ECMWF forecast model: Cirrus clouds appear at humidities below ice-saturation and any vapour in excess of saturation is transferred to the ice phase.

Ponater et al. (1996b) have shown a way out of this dilemma. In developing a contrail parametrisation for the climate model ECHAM (Roeckner et al., 1996), they were faced with a similar problem: The model humidity is a mean value for a rather large grid box. In nature, local supersaturation and hence cloud formation is already achieved whereas the corresponding grid box mean humidity is far below saturation. Therefore, in the ECHAM model cirrus clouds are formed when the relative humidity $U$ (with respect to ice) exceeds a threshold value $\left(U_{\mathrm{Ci}}=0.6\right)$. The fractional coverage of cirrus, $b_{\mathrm{Ci}}$, increases from 0 at the threshold to 1 at icesaturation. This approach of parametrising clouds leads to climatological cloud distributions that are in reasonable agreement with observed distributions (Chen and Roeckner, 1997).

Ponater et al. (1996b) developed a contrail parametrisation that is consistent with the way clouds are formed in the ECHAM model and that allows contrails to form before cirrus clouds appear, as can often be observed in reality. Details of this scheme are found in Appendix A. Here, we only present a short overview. The threshold value for total high cloud formation (i.e. contrail plus cirrus) is obtained by including the Schmidt-Appleman theory in the parametrisation scheme. When pressure and temperature are given, it is possible to compute a critical relative humidity $U^{*}(p, T)$ (relative to liquid water, therefore $\left.U^{*} \leq 1\right)$, which must be exceeded when contrails (both persistent and short-living) form. Ponater et al. then define a modified threshold humidity for contrails by multiplying $U_{\mathrm{Ci}}$ with $U^{*}(p, T)$. This yields a total fractional coverage, $b_{\text {tot }}$, and the contrail coverage is then obtained by subtracting the cirrus coverage $b_{\mathrm{Ci}}$ from $b_{\text {tot }}$. This ansatz takes into account the fact that the identification levels of contrails decrease with increasing natural cloudiness, because as the humidity approaches saturation the natural cloudiness approaches that of an overcast sky leaving no room for additional contrails. Note that the contrail coverage derived in this way is a potential contrail coverage, i.e. it is a measure of the ability of the air to carry contrails. It is an upper bound for the actual contrail coverage, i.e. the actual value cannot exceed the potential value even if air traffic grew to infinity. The potential contrail coverage alone does not say anything about the actual contrail cover as long as we have not yet included information about the level of air traffic.

When calculating $U^{*}(p, T)$ we usually assume an overall propulsion efficiency $\eta=0.3$, which is representative for present day aircraft (see Appendix B). The sensitivity to the choice of $\eta$ is studied in Section 4.4. Furthermore, a water vapour emission index of $E I_{\mathrm{H}_{2} \mathrm{O}}=1.25 \mathrm{~kg}\left(\mathrm{H}_{2} \mathrm{O}\right) /$ $\mathrm{kg}$ fuel and a combustion heat of $Q=43 \mathrm{MJ} / \mathrm{kg}$ fuel was assumed (Schumann, 1996).

In order to determine a realistic value for the fractional coverage of contrails (instead of maximum or potential values) we have to take into account the frequency of air traffic at a given location and time. As no inventory of such data currently exists, we use the aircraft fuel consumption per grid box and time unit as a substitute (cf. Section 2.2).

If air traffic density is low, one may assume that every flight adds linearly to the observed 
contrail coverage. On the other hand, higher densities of air traffic will cause saturation effects, e.g. by contrail merging or consumption of condensable water vapour. If the sky is already heavily covered with contrails, an additional flight will add less to the total cloudiness than compared to the cloud-free case. We make two extreme assumptions: (1) At given background conditions the contrail coverage is proportional to the fuel consumption (low density assumption). (2) The contrail coverage is proportional to the square root of fuel consumption (high density assumption). Using a simple model of air traffic and contrail expansion, Gierens (1998) demonstrated that in most situations it is a reasonable choice to relate contrail fractional cover to the are traffic density in a linear fashion. Saturation effects only show up for extreme situations, e.g. very strong wind-shear or narrow air routes without upper level winds. For both low and high density assumptions, we have to calibrate the output with a non-physical factor. This factor is chosen such that our diagnosed average fractional contrail coverage fits the Bakan et al. (1994) results, i.e. the annual mean contrail coverage should be $0.5 \%$ in the longitude/latitude region from $30^{\circ} \mathrm{W}$ to $30^{\circ} \mathrm{E}$ and from $35^{\circ} \mathrm{N}$ to $75^{\circ} \mathrm{N}$.

In order to obtain the total contrail coverage, fractional coverages for individual levels are summed up using the random overlap assumption (Manabe and Strickler, 1964) for (actual) contrails:

$b_{\text {sum }}=1-\prod_{k}\left(1-b_{k}\right)$,

where $b_{k}$ is the fractional coverage pertaining to pressure level $k$. For clouds with larger vertical extension than contrails, like cirrus, or for air masses that are able to carry contrails (i.e. potential contrails), we assume maximum overlap, if these objects extend through two or more adjacent levels. If there is a gap (i.e. one or more clear levels with $b_{k}=0$ ) then we assume random overlap for the objects that are separated by the gap (Geleyn and Hollingsworth, 1978). The formulation is as follows:

$b_{\text {sum }}=1-\left(1-b_{1}\right) \prod_{k>1} \frac{1-\max \left(b_{k}, b_{k-1}\right)}{1-\min \left(b_{k-1}, 1-\varepsilon\right)}$, where $\varepsilon$ is a very small positive number (introduced for purely numerical reasons).

For the summation of the coverage of potential contrails we first add the total (cirrus plus potential contrails) and the cirrus coverage using the above method. The coverage of potential contrails alone is then given by the difference between these two quantities.

\section{Results and Discussion}

\subsection{Potential Contrail Formation}

As noted above, the potential contrail coverage is a measure of the ability of the air to allow contrail formation. This quantity, in particular when it is averaged over a long time, can be plausibly interpreted as the fraction of aircraft that give rise to contrails at any respective location. Figure 2 shows the mean potential contrail coverage, as obtained from 11 years (1983-1993) of re-analysis data in $2.8^{\circ} \times 2.8^{\circ}$ resolution. The results are shown separately for the 5 pressure levels $(150,200,250,300$ and $400 \mathrm{hPa}$ ) and summarised over all 7 (i.e. incl. 100 and $500 \mathrm{hPa}$ ) levels considered, according to the maximum/random overlap assumption as described at the end of Section 3.

Contrail formation usually occurs in a layer below the tropopause, where it is cold and moist enough to fulfil the Schmidt-Appleman criterion. At lower altitudes, it is too warm, such that even short-lived contrails would not appear. At higher levels, in particular in the stratosphere, it is usually too dry for contrails to form. This suggests that the regions of potential contrail formation actually follow the mean location of the tropopause, and this is indeed shown in Fig. 2. Potential contrail formation is strongest at high altitudes (150-200 hPa) over the tropics, where it is very cold and where sufficient moisture is available because of tropical convection. At lower altitudes, the regions that are susceptible to the formation of contrails are located more in the extra-tropics. In the tropics it is too warm at these levels, hence contrails cannot form. The average and maximum values of potential contrail formation are much higher (almost reaching 30\%) in the tropics than in the mid and high latitudes. The overall mean value (for the total layer between 100 and $500 \mathrm{hPa}$ ) 


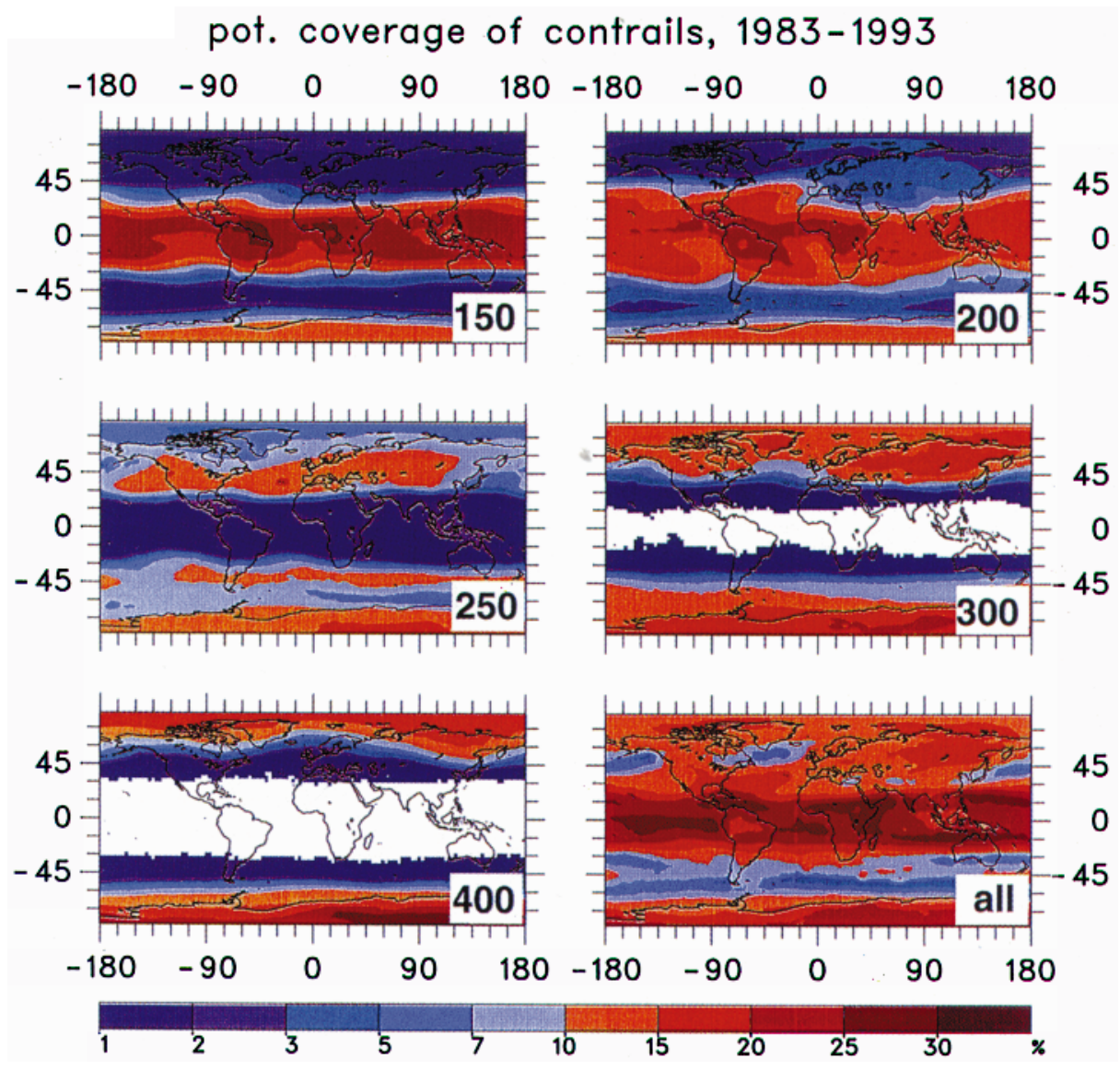

Fig. 2. Annual mean potential contrail coverage $[\%]$ at various altitudes and as a total coverage for the layer from 100 to $500 \mathrm{hPa}$

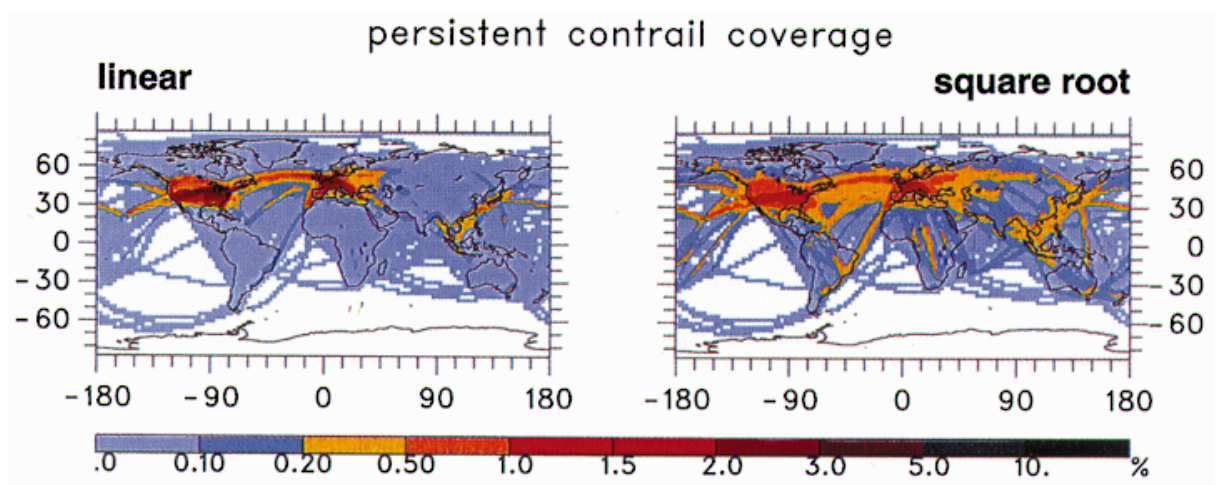

Fig. 3. Annual mean contrail coverage [\%] (mean of the years 1983-1993) as obtained for linear (left panel) and square root weighting (right panel) of the fuel consumption. The calibration produces a mean value of $0.5 \%$ for the region extending from $30^{\circ} \mathrm{W}$ to $30^{\circ} \mathrm{E}$ and from $35^{\circ} \mathrm{N}$ to $75^{\circ} \mathrm{N}$

is $16 \%$ (Table 1). This number is similar to the global mean coverage of cirrus clouds $(23 \%$ over land, $13 \%$ over the oceans, see Warren et al., 1986, 1988). This means that the amount of high cloud cover (contrails, contrail induced cirrus and natural cirrus) could almost double if aircraft flew everywhere. The mean value over Europe is $12 \%$, which compares well with the 




impact of flight altitude on persistent contrail coverage $+\mathbf{1 k m}$

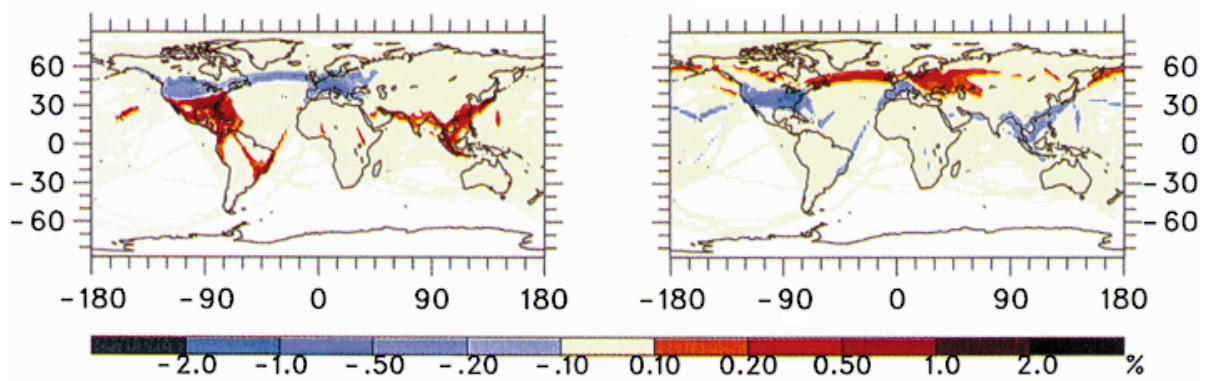

Fig. 4. Seasonal variation of the present day contrail coverage [\%] (linear weighting of fuel consumtion)

Fig. 5. Change in contrail coverage when the current air traffic is shifted $1 \mathrm{~km}$ upward (left panel) or downward (right panel)

Table 1. Contrail Converage and Potential Contrail Coverage [\%] for Various Regions of the World as Derived from our Model Calculations. Averages over the Period 1983-1993 are Listed. If not Specified Otherwise. Linear Weighting, Actual Cruise Altitude and $\eta=0.3$ are Assumed

\begin{tabular}{lcccccc}
\hline & $\begin{array}{l}\text { Reference } \\
\text { region }^{a}\end{array}$ & Europe & NAFC $^{b}$ & USA & SE-Asia $^{c}$ & World $^{\text {(n) }}$ \\
\hline Potential contrail cover & 12.0 & 12.1 & 12.3 & 14.1 & 21.1 & 16.0 \\
Contrail cover (linear) & $0.50^{d}$ & 1.07 & 0.43 & 1.44 & 0.12 & 0.09 \\
Contrail cover (square root) & $0.50^{d}$ & 0.84 & 0.42 & 0.89 & 0.23 & 0.13 \\
Contrail cover (Jan.) & 0.54 & 1.16 & 0.46 & 1.63 & 0.13 & 0.09 \\
Contrail cover (Apr.) & 0.51 & 1.10 & 0.49 & 2.04 & 0.13 & 0.11 \\
Contrail cover (July) & 0.32 & 0.63 & 0.30 & 0.50 & 0.10 & 0.06 \\
Contrail cover (Oct.) & 0.63 & 1.38 & 0.48 & 1.60 & 0.13 & 0.10 \\
Cruise altitude 1 km higher & 0.33 & 0.74 & 0.38 & 1.36 & 0.23 & 0.10 \\
Cruise altitude 1 km lower & 0.53 & 1.04 & 0.40 & 1.04 & 0.00 & 0.07 \\
Propulsion efficiency $\eta=0.25$ & 0.47 & 1.00 & 0.41 & 1.35 & 0.10 & 0.08 \\
Propulsion efficiency $\eta=0.35$ & 0.53 & 1.13 & 0.46 & 1.53 & 0.13 & 0.09 \\
\hline
\end{tabular}

${ }^{a} 30^{\circ} \mathrm{W}-30^{\circ} \mathrm{E}, 35^{\circ} \mathrm{N}-75^{\circ} \mathrm{N}$ as in Bakan et al. (1994)

${ }^{b}$ North-Atlantic Flight Corridor, $82^{\circ} \mathrm{W}-14^{\circ} \mathrm{E}, 28^{\circ} \mathrm{E}, 28^{\circ} \mathrm{N}-72^{\circ} \mathrm{N}$

${ }^{c} 90^{\circ} \mathrm{E}-130^{\circ} \mathrm{E}, 10^{\circ} \mathrm{S}-25^{\circ} \mathrm{N}$

${ }^{d}$ per definitionem (gauge value) 
estimate given by Mannstein et al. (1998). South-East Asia shows a mean value as high as $21 \%$.

The potential for the formation of contrails also varies seasonally (not shown). The moist areas where contrails can form occur most frequency in the winter hemispheres. This behaviour reflects the annual temperature variation, which is negatively correlated to the variation of relative humidity above $850 \mathrm{hPa}$ at mid-latitudes (Peixoto and Oort, 1996). Hence, contrail appearance is much more probable in winter than in summer. Since the annual variability of air traffic density is weak (Gardener et al., 1997), the actual contrail statistics should reflect the seasonal variability of the appearance of these moist areas.

\subsection{Contrail Coverage due to Present Day Levels of Air Traffic}

Contrail coverage is assumed to be determined by meteorological parameters, i.e. thermodynamic state of the atmosphere (cf. Section 4.1), and by the frequency of air traffic. As mentioned in Section 2.2 we use the fuel consumption according to the DLR-2 inventory (Schmitt and Brunner, 1997) as a substitute for the frequency of air traffic. We ignore the fact that air traffic increased during the period of the meteorological data (1983-1993) and so we take the 1991/92 value for the whole period.

Figure 3 shows the annual mean contrail coverage (mean over 1983-1993), as obtained with linear and square root weightings of fuel consumption and after calibration (see Section 3 ). The global mean contrail coverage is 0.09 and $0.13 \%$ for linear and square root weightings, respectively (Table 1). The air routes can clearly be seen as regions of enhanced contrail cloudiness in both panels of Fig. 3. With the linear weighting the maxima are higher (more than 5\% over certain regions in USA), and the regions with a high contrail coverage are confined to narrower regions than with the square root weighting. Interestingly, the latter case leads to higher contrail coverage in regions of sparse air traffic and, in effect, to a smoother picture than with linear weighting. In both cases, the most outstanding regions are the USA, Europe, and South-East Asia with mean fractional contrail coverages (linear weighting) of $1.44 \%, 1.07 \%$ and $0.12 \%$, respectively (Table 1 ). The potential for additional contrail formation due to growing air traffic is therefore still far from being exhausted, as a comparison of Figs. 2 and 3 reveals.

The seasonal variation of contrail coverage (Fig. 4) follows the seasonal variation of the appearance of the cold moist areas as discussed above, i.e. a minimum in July and a maximum in October for the reference region extending from $30^{\circ} \mathrm{W}$ to $30^{\circ} \mathrm{E}$ and from $35^{\circ} \mathrm{N}$ to $75^{\circ} \mathrm{N}$ (western Europe and the adjacent North Atlantic). This result contradicts the observational results of Bakan et al. (1994), who found a maximum in summer. However, our result is consistent with the seasonal variation of temperature in the upper troposphere. Temperature and relative humidity are negatively correlated in the mid-latitudes above $850 \mathrm{hPa}$ (Peixoto and Oort, 1996), which implies a greater probability of contrail formation in winter and a smaller one in summer. Objective observations of contrails are obtained from automatically analysed satellite images (Mannstein et al., 1998). A first evaluation of one annual cycle (1996) of contrail coverage over Germany shows a minimum in July, and a maximum in October (Mannstein et al., 1998), which is consistent with the present results.

As a maximum in cirrus cloud coverage is found in winter over the USA (Warren et al., 1986), it is not surprising that the maximum contrail cloudiness is also found in winter and spring, and a distinct minimum $(0.5 \%)$ occurs in July. This is consistent with results obtained from direct observations by US Air Force crews from May 1990 to April 1991 (Peters, 1993) and surface based observations from April 1993 to April 1994 (Minnis et al., 1997). Ponater et al. (1996b) found the same seasonal variation of contrail coverage over USA in the ECHAM general circulation model which was supplied with the new contrail parametrisation scheme. Our results for the USA strongly depend on the current choice of flight altitudes (cf. Section 4.3).

It would be interesting to identify a trend in contrail coverage, which may exist due to changes in air traffic density or climate. However, as there is only eleven years in the current data base, and only one year data base of fuel 
consumption available, we regard such an analysis as inappropriate.

\subsection{The Impact of Flight Altitude}

Here we investigate how contrail cloudiness would change if the flight cruise altitudes were shifted up or down by $1 \mathrm{~km}$. The result is displayed in Fig. 5 for linear weighting. There is a distinct dichotomy between tropical and extra-tropical zones. Shifting the cruise altitudes upward diminishes contrail cloudiness at midlatitudes, because a lot of air traffic then occurs in the (dry) stratosphere. At present, already about $40 \%$ of the air traffic in the North Atlantic flight corridor is above the tropopause (Hoinka et al., 1993). On the other hand, shifting the cruise altitudes $1 \mathrm{~km}$ downward brings much of stratospheric flights into the (moist) troposphere. This results in more contrails in the extra-tropics. Notable exceptions are over the USA and Europe, where a lot of air traffic is short-range and therefore occurs at low cruise levels. Shifting this traffic even further down brings it into zones too warm for contrail formation.

In the tropics aircraft always fly a few kilometres below the tropopause, in contrary to the mid-latitudes. Thus, the cruise levels can be shifted $1 \mathrm{~km}$ up without entering the stratosphere. Figure 2 shows that the potential for contrail formation is largest in the tropics at the highest altitudes, just below the tropopause. Hence, by shifting the cruise levels upward in the tropics, the contrail coverage is likely to increase. Over South-East Asia this would mean a near doubling of the contrail cloudiness relative to the actual traffic (Table 1). On the other hand, the number of contrails would be diminished if the air traffic in tropical zones was shifted to lower altitudes where it is too warm for contrail formation. In this case the fractional contrail coverage would be less than $0.1 \%$ at any location in the tropics, i.e. the contrails would disappear almost completely from the tropical zone.

If the air traffic occurred $1 \mathrm{~km}$ higher than today, the seasonal variation of contrail cloudiness over the USA would be reversed. In this case, a strong maximum in the summer months would arise, while in the winter a minimum would occur. In this respect, North America is exceptional, probably because of strong north- ward transport of water vapour from the Gulf of Mexico during summer (see Peixoto and Oort, 1996). The temperature in the upper troposphere does not increase much in summer, hence the potential for contrail formation increases because of vapour advection. In turn, at the usual flight altitudes, the summer temperature increase outweighs the moisture increase, leading to the observed summer contrail minimum. On the other hand, a downward shift of the flight levels would not change the seasonal variation of contrail occurrence over the USA. Over Europe, the seasonal variation of contrail cloudiness is not affected by a vertical shift in the air traffic.

\subsection{Impact of Propulsion Efficiency}

Besides ambient conditions, the Schmidt-Appleman criterion depends on fuel characteristics and on the propulsion efficiency $\eta$ of an aircraft (see Appendices, and Schumann, 1996). The more the fuel's chemical energy is used to propel the aircraft, the less warm the exhaust gas is, and a larger relative humidity is reached during the mixing of the exhaust with the ambient air. Schumann (1996) shows that the threshold temperature for contrail onset increases by about $1.4 \mathrm{~K}$ per 0.1 increase in propulsion efficiency implying that contrails form at about $370 \mathrm{~m}$ lower altitude. Thus, better engines are expected to yield more contrails. The mean propulsion efficiency of the present fleet is $0.30 \pm 0.05$ (Doepelheuer, DLR, personal communication, 1997). In order to test the impact of propulsion efficiency on the fractional contrail coverage, we repeated the diagnosis with $\eta=0.25$ and $\eta=0.35$, where the smaller value is representative of low-bypass turbofans.

The relative change of the computed contrail coverage due to variations in the propulsion efficiency is of the order of $10 \%$ for all regions listed in Table 1. However, the absolute impact of these variations of the propulsion efficiency on the contrail coverage is small, less than $\pm 0.1 \%$ of the area at most locations over the globe. The probable reason for this very weak impact is that most air traffic occurs under conditions, where the background temperature is not close to the threshold temperature, i.e. outside a range of $\pm 0.7 \mathrm{~K}$ around the critical temperature for contrail onset for $\eta=0.30$. 
There are a few locations where the absolute effect of a change of $\eta$ is larger (with maxima exceeding $\pm 0.2 \%$ of the area), e.g. southern Japan, middle Europe and - most prominently the eastern part of USA. Most probably, there is a lot of short-range traffic, that does not reach high cruise altitudes with temperatures much less than $-40{ }^{\circ} \mathrm{C}$. The background atmosphere is then more often close to threshold conditions than in the higher and colder levels, and this results in a higher sensitivity of contrail coverage to the mean propulsion efficiency.

\subsection{Comparison with high Cloud Statistics}

Persistent contrails may be considered a special kind of cirrus, and the formation conditions of these cloud types are related. Both require ice saturation and, according to a number of studies (e.g., Sassen and Dodd, 1989; Heymsfield and Miloshevich, 1993; Ström et al., 1997), the most important nucleation pathway of cirrus ice crystals is the freezing of haze droplets and this requires humidities near water saturation. Thus it seems worthwhile to compare cirrus cloud statistics obtained from satellite measurements (Wylie et al., 1994; Wang et al., 1996) with the corresponding statistics obtained from the reanalysis data. Such a comparison is also a quality control test for these data and for our method.
Applying the ECHAM cirrus parametrisation (Appendix A) to the re-analysis data, we determined an annual mean coverage of natural cirrus clouds. As before, maximum and random overlaps, respectively, were used to calculate the total coverage of the layer from 100 to $500 \mathrm{hPa}$. Figure 6 shows the annual mean coverage for the 11 years period from 1983 to 1993 . The resulting mean cover is $16 \%$, which is some percent less than observational values given in the maps by Warren et al. (1986, 1988). This reflects the fact that the ECMWF model already builds clouds, and we are dealing here with the humidity that remains after the clouds have been formed. However, we are merely comparing structures here, not absolute values, so this underestimate does not hamper our comparison.

Pronounced maxima are found over the Amazon basin, over central Africa and over a broad band centred around the Indonesian archipelago, i.e. along the Inner Tropical Convergence Zone (ITCZ). These maxima are congruent with the maxima in sub-visible cloud occurrence found by Wang et al. (1996) in SAGE II data (their Plate 1). It is not surprising that also the upper-tropospheric humidity has maximum values over the regions considered (Soden and Lanzante, 1996, their Fig. 2). Obviously, the occurrence of sub-visual cirrus in the equatorial zone is triggered by deep convection, which

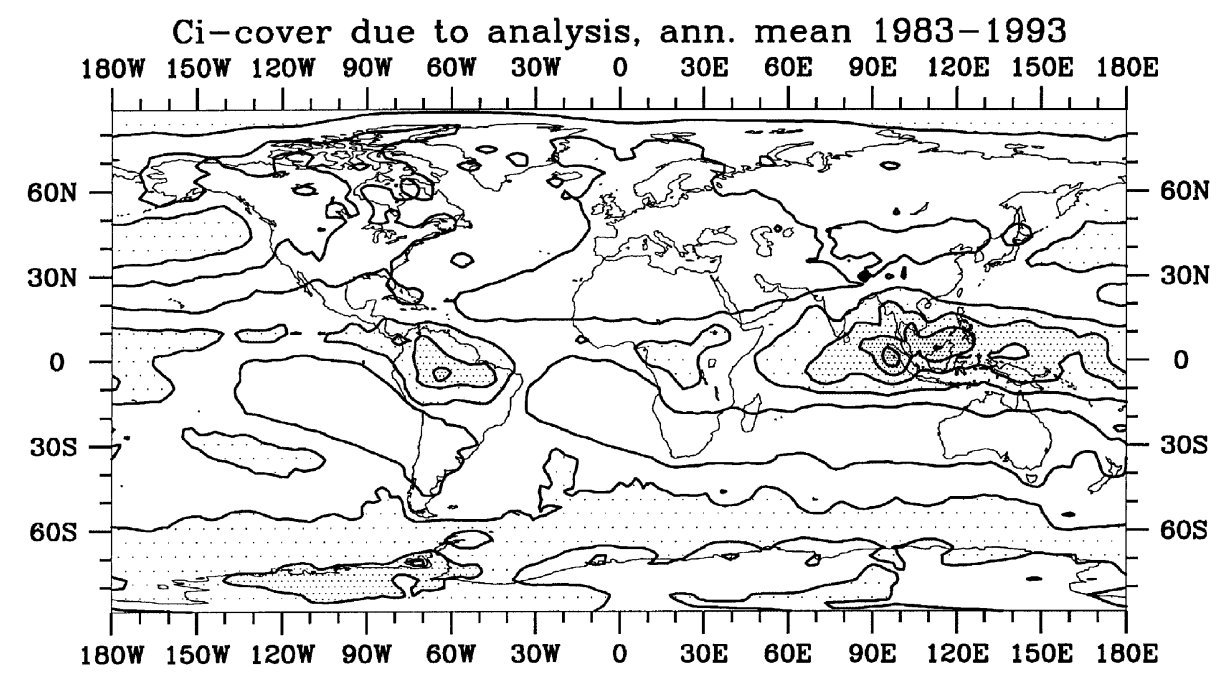

Fig. 6. Annual mean coverage [\%] by natural cirrus clouds as determined with application of the ECHAM cloud scheme to the ECMWF re-analysis data. Plotted is the total coverage of the layer from between 100 and $500 \mathrm{hPa}$ for the eleven years period 1983-1993. Contour lines start with the $10 \%$ contour and the increment between them is $10 \%$. The stippling begins at $20 \%$ and its density increases at each higher contour 
transports humidity from the boundary layer to the tropopause and even beyond (Soden and Fu, 1995).

An analysis of the annual cycle of the derived cirrus distribution makes the shift of the ITCZ obvious by a moving maximum (not shown). Low values are found in the sub-tropical subsidence zones. The same structures are essentially found by Wylie et al. (1994) in the frequency distribution of transmissive clouds (i.e. sub-visible cirrus), as obtained from evaluation of HIRS data.

Figure 6 shows frequencies more than $20 \%$ of ice clouds over much of the polar zones, which is not consistent with the distribution of (subvisible) cirrus. The appearance of ice clouds in polar regions might be an artefact of the cirrus parametrisation employed, because in nature the mere fact of high humidity does not necessarily imply formation of clouds. An interpretation of the polar maximum in Fig. 6 as an indication of high relative humidity is consistent with the distribution of upper-tropospheric (relative) humidity presented by Soden and Lanzante (1996). Interestingly, if the upper-tropospheric humidity is plotted in terms of mixing ratio (Read et al., 1995), the polar maximum is absent. This might explain the absence of sub-visible cirrus: there is too little water to form clouds, although it is sufficient to be above ice saturation due to the low temperatures in the polar zones.

\subsection{Limitations of the Present Analysis}

Our results may suffer from several limitations. The results depend on the accuracy of the temperature and humidity data given by ECMWF. The extent of the potential contrail formation regions may depend on spatial resolution. The actual cloud cover and the climatic properties of the persistent contrails will depend not only on the thermodynamic conditions and the fuel consumption but also on rising or sinking air motions, wind shear and turbulence (Freudenthaler et al., 1995), the amount of water available for ice formation, and the micro-physical processes of contrail and cirrus formation (Kärcher et al., 1996). A full investigation of all these processes and parameters is beyond the scope of this study. Rather, this study is supposed to provide a first plausible estimate of the global potential for contrail formation and the actual global contrail cloud coverage.

The most serious limitation is probably the use of initialised data from the NWP model instead of measured data for the upper tropospheric humidity. The cloud scheme already produces clouds below ice-saturation which uses up a certain fraction of the water vapour, so that we are dealing with the humidity that remains after cloud formation and that never exceeds icesaturation. The effect of this on the computed global mean cirrus cover might be considerable. However, we may be confident that the effect on the potential contrail cover is small, since maxima of the latter quantity occur at relatively low or even vanishing natural cloudiness values. The effect on the actual contrail coverage is probably small because the use of a gauge factor guarantees that the results are close to observed values. Also, the different amounts of cirrus cloudiness for different regions can lead to varying degrees of underestimation of potential contrail cloudiness which may impact the computed spatial contrail distribution. For validation, it would be highly desirable to have comparable satellite observations of contrails in various regions of the world.

\section{Conclusions and Outlooks}

Using ECMWF re-analyses we diagnosed the potential global contrail coverage by detecting those regions of the atmosphere where the recently developed contrail parametrisation for the climate model ECHAM indicates the potential for contrail formation (Ponater et al., 1996b). The global and annual mean potential contrail coverage is $16 \%$ for the layer between 100 and $500 \mathrm{hPa}$. The ITCZ is most favourable for contrail formation, in particular at altitudes above $200 \mathrm{hPa}$. Between 250 and $300 \mathrm{hPa}$, the mid-latitudes show a secondary maximum of potential contrail coverage.

The actual present day contrail coverage was obtained by multiplying the potential contrail coverage with the fuel use according to the DLR2 aircraft emissions inventory after normalisation. As expected the main flight routes are highlighted. The maximum cover is about $5 \%$ over Eastern USA. The annual global mean value is $0.09 \%$. 
A serious limitation of the present study is the need to use initialised analyses of humidity, which are means representing rather large areas. This implies that the given humidities are influenced by the cloud scheme of the ECMWF forecast model, wherein cirrus formation generally limits the humidity to ice-saturation. This made it necessary to use a contrail parametrisation for a climate model instead of directly evaluating indicator variables (as e.g., in Gierens et al., 1997).

Despite the fact that air traffic densities are quite homogeneous throughout the year, the computed contrail coverage exhibits a pronounced annual cycle. At mid-latitudes, higher values are found during winter than during summer, which is consistent with most satellite retrievals and in situ observations. The contrail coverage is locally rather sensitive to flight altitude. However, the computed global mean value is rather insensitive to variations in flight level. If all aircraft were flying $1 \mathrm{~km}$ higher (lower) the global mean contrail coverage would stay nearly unchanged (decrease $0.02 \%$ of the area). This rather small change is due to compensating effects. If aircraft fly higher (lower), the contrail coverage increases (decreases) in low latitudes, whereas less (more) contrails are observed in mid-latitudes.

The mean contrail coverage in this analysis increases by about $\pm 10 \%$ (relatively) for an increase of the propulsion efficiency from 0.25 to 0.35 . However, the absolute change of the computed contrail coverage due to variations of the propulsion efficiency is small at present, as in most cases the thermodynamic state of the atmosphere is far from the critical threshold value according to the Schmidt-Appleman criterion, or much of the air traffic occurs at high altitude where the Schmidt-Appleman criterion is met anyway. Our diagnosis of regions which are conditioned to form cirrus clouds is supported by SAGE and HIRS satellite observations of (sub-visible) cirrus clouds. Our diagnosis reveals that the present contrail coverage is far from saturation. All forecasts of air traffic predict a rather rapid growth until 2015. Hence, we expect a further increase in the global contrail coverage. By means of a general circulation model both the future contrail coverage and its climate impact can be estimated.
In future studies, we plan to determine the contrail cover for a future air traffic scenario. In addition one might investigate the overlap with cirrus formation, e.g., by applying the cirrus analysis scheme as used by the ECMWF forecast model. The radiative impact of various air traffic modes may be assessed using the results from the present study when augmented with estimates of the optical properties of contrails in various regions. Finally, we plan to explore the correlation between thermodynamic conditions and regions where the SAGE data detected subvisible cirrus which are apparent when comparing our results with those of Wang et al. (1996). A strong correlation would imply that such cirrus clouds are mainly determined by the thermodynamic state of the atmosphere and only partly by micro-physics.

\section{Appendix A: Contrail Parametrisation}

The fractional cloud cover of cirrus clouds is parametrised as a function of relative humidity over ice, $U_{\mathrm{i}}$, viz.

$b_{\mathrm{Ci}}=1-\left[\frac{1-\max \left(U_{\mathrm{i}}, U_{\mathrm{Ci}}\right)}{1-U_{\mathrm{Ci}}}\right]^{1 / 2}$,

where $U_{\mathrm{Ci}}=0.6$ is a threshold value which must be exceeded for cirrus clouds to form in the model. The parametrisation for contrails plus cirrus is identical to that for cirrus alone but for the choice of the threshold humidity, which is given by the product of $U_{\mathrm{Ci}}$ with a critical humidity $U^{*}$, that is obtained from a reformulation of the Schmidt-Appleman criterion:

$U^{*}=\left[G\left(T-T_{\mathrm{LM}}\right)+e_{\text {sat }}\left(T_{\mathrm{LM}}\right)\right] / e_{\text {sat }}(T)$,

where $e_{\text {sat }}$ is the saturation vapour pressure with respect to a plane of liquid water, and $G$ is the ratio of the rates of change of vapour pressure and temperature in an expanding aircraft exhaust plume, which is given by (Schumann, 1996; his Eq. 8):

$G=\left[E I_{\mathrm{H}_{2} \mathrm{O}} c_{p} p\right] /[\varepsilon Q(1-\eta)]$.

Here, $p$ and $c_{p}$ are the pressure and the specific heat at constant pressure, $E I_{\mathrm{H}_{2} \mathrm{O}}$ is the emission index of water vapour (which is $1.25 \mathrm{~kg}$ per $\mathrm{kg}$ fuel burnt), $\varepsilon=0.622$ is the ratio of molecular masses of water and air, $Q=43 \mathrm{MJ} / \mathrm{kg}$ fuel is the specific combustion heat of kerosene, and $\eta$ is the propulsion efficiency of a jet engine (see Appendix B).

$T_{\mathrm{LM}}$ is (for given $G$ ) the maximum temperature at which contrails can form. A good approximation has been provided by Schumann (1996; his Appendix 2):

$$
\begin{aligned}
T_{\mathrm{LM}}= & -46.46+9.08 \ln (G-0.053) \\
& +0.720[\ln (G-0.053)]^{2},
\end{aligned}
$$

where the temperature is in ${ }^{\circ} \mathrm{C}$ and $G$ is in $\mathrm{Pa} / \mathrm{K}$. 


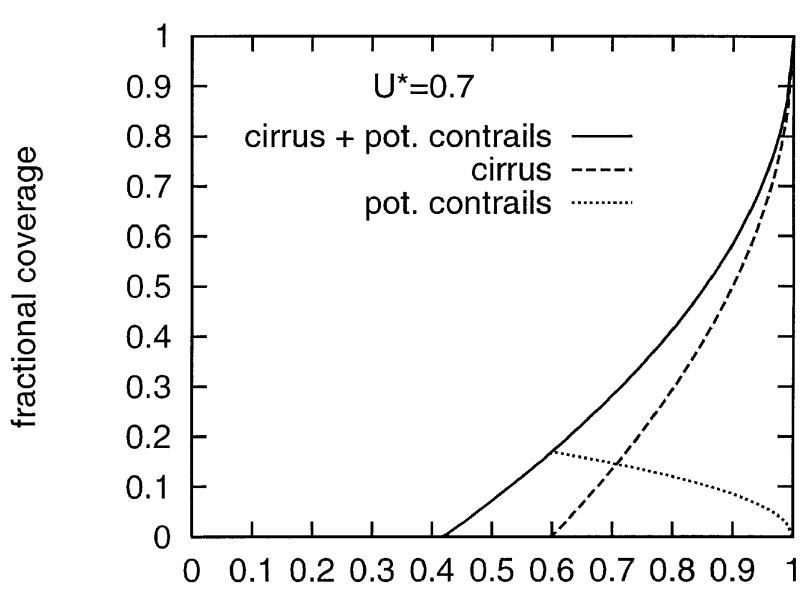

rel. humidity over ice

Fig. 7. Parametrised coverage for natural clouds (dashed), for the sum of natural clouds and potential contrails (solid), and for potential contrails alone (dotted) in the case of a critical relative humidity $U^{*}=0.7$. The coverage of potential contrails is given by the (vertical) difference between the solid and dashed curves

The result of the contrail parametrisation for a critical humidity of $U^{*}=0.7$ is shown in Fig. 7. The fractional coverage of potential contrails has a maximum at the threshold for cirrus formation when contrails are still the only form of ice clouds. For the presented situation the maximum potential contrail cover is about $16 \%$.

\section{Appendix B: Propulsion Efficiency}

The mean overall propulsion efficiency $\eta$ measures the amount of propulsion work per chemical energy provided by the fuel. The higher $\eta$, the cooler is the exhaust for given water vapour content, and the earlier the aircraft may trigger contrail formation. The value $\eta$ is determined by the specific fuel consumption $S F C$, i.e. the fuel flow rate $\dot{m}_{f}$ per thrust $F$ of the engine $\left(S F C=\dot{m}_{f} / F\right)$, the aircraft speed $V$, and the combustion heat $Q, \eta=V /(Q \cdot S F C)$. The value of $Q$ is close to $43 \mathrm{MJ} / \mathrm{kg}$ within narrow error bands. Estimates for the values of $S F C$ and $V$ were provided by engine experts at the Working Group meeting CAEP-4, WG 3, of ICAO (International Civil Aviation Organization, Montreal), May 20-23, 1997, Savannah, Georgia (unpublished). From this information we determined that the $\eta$-value of sub-sonic aircraft at cruise was close to 0.22 for engines certificated in the 1950s, near 0.37 for modern engines in the early 1990s, is expected to exceed 0.4 for new engines to be built by 2010 , and may reach 0.5 by 2050 . Data on specific fuel consumption and aircraft speed for the present fleet of sub-sonic aircraft (Dipl.-Ing. Doepelheuer, DLR, personal communication, 1997) imply an $\eta$ of $0.30 \pm 0.05$ for this fleet. The standard deviation is computed in order to account for the fuel consumption rates of various aircraft/ engine types. An increase of $\eta$ from 0.3 to 0.5 in a standard atmosphere causes formation of contrails in ambient air about $2.8 \mathrm{~K}$ warmer or at $770 \mathrm{~m}$ lower altitude (Schumann, 1996).

\section{Acknowledgements}

This work was funded by the Verbundprogramm "Schadstoffe in der Luftfahrt" of the Bundesministerium für Bildung, Wissenschaft, Forschung und Technologie. The authors are grateful to Drs. Christian Jakobs and Adrian Simmons from ECMWF and Dr. Martin Stendel from the MPI für Meteorologie for helpful discussions on the ECMWF cloud scheme and the ECMWF re-analysis (ERA) data. The ERA data were provided by ECMWF within the Special Project "The climatology of the global tropopause". We would like to thank Dr. Ines Köhler and Ms. Sigrid Lerke from the DLR-Institut für Physik der Atmosphäre for providing the DLR-2 aircraft inventory in suitable form and for their assistance in processing the contrail coverage data. Dipl.-Ing. Andreas Doepelheuer from the DLR-Institut für Antriebstechnik provided data on the specific fuel consumption and cruise speed of presently operating aircraft from which we estimated the presently valid overall propulsion efficiency. A preliminary analysis of the kind presented here was performed by Mr. Dietrich Brockhagen.

\section{References}

Appleman, H., 1953: The formation of exhaust condensation trails by jet aircraft. Bull. Amer. Meteor. Soc., 34, 14-20.

Bakan, S., Betancor, M., Gayler, V., Grass, H., 1994: Contrail frequency over Europe from NOAA-satellite images. Ann. Geophysicae, 12, 962-968.

Brasseur, G. P., Cox, R. A., Hauglustaine, D., Isaksen, I., Lelieveld, J., Lister, D. H., Sausen, R., Schumann, U., Wahner, A., Wiesen, P., 1998: European scientific assessment of the atmospheric effects of aircraft emissions. Atmos. Environ., 32, 2329-2418.

Chen, C. T., Roeckner, E., 1997: Cloud simulations with the Max-Planck-Institute for Meteorologie general circulation model ECHAM4 and comparison with observations. J. Geophys. Res., 102, 9335-9350.

Freudenthaler, V., Homburg, F., Jäger, H., 1995: Contrail observations by ground-based scanning lidar: cross-sectional growth. Geophys. Res. Lett., 22, 3501-3504.

Gardener, R., Adams, K., Cook, T., Deidewig, F., Ernedal, S., Falk, R., Fleuti, E., Herms, E., Johnson, C. E., Lecht, M., Lee, D. S., Leech, M., Lister, D., Masse, B., Metcalfe, M., Newton, P., Schmitt, A., Vandenbergh, C., van Drimmelen, R., 1997: The ANCAT/EC global inventory of NOx emissions from aircraft. Atmos. Environ., 31, 17511766.

Geleyn, J. F., Hollingsworth, A., 1978: An economical analytical method for the computation of the interaction between scattering and line absorption of radiation. Beitr. Phys. Atmos., 52, 1-16.

Gibson, J. K., Kallberg, P., Uppala, S., Hernandez, A., Nomura, A., Serrano, E., 1997: ERA Description. ECMWF Re-Analysis Project Report Series, 1, 1-72. 
Gierens, K., 1998: How the sky gets covered with contrails. Meteorol. Z., N. F. 7, 181-187.

Gierens, K. M., Schumann, U., Smit, H. G. J., Helten, M., Zängl, G., 1997: Determination of humidity and temperature fluctuations based on MOZAIC data and parametrisation of persistent contrail coverage for general circulation models. Ann. Geophysicae, 15, 1057-1066.

Heymsfield, A. J., Miloshevich, L. M., 1993: Homogeneous ice nucleation and supercooled liquid water in orographic wave clouds. J. Atmos. Sci., 50, 2335-2353.

Hoinka, K. P., Reinhardt, M. E., Metz, W., 1993: North Atlantic air traffic within the lower stratosphere: Cruising times and corresponding emissions. J. Geophys. Res., 98, 23113-23131.

Kalnay, E., Kanamitsu, M., Kistler, R., Collins, W., Deaven, D., Gandin, L., Iredell, M., Saha, S., White, G., Woollen, J., Zhu, Y., Chelliah, M., Ebisuzaki, W., Higgins, W., Janowiak, J., Mo, K. C., Ropelewski, C., Wang, J., Leetma, A., Reynolds, R., Jenne, R., Joseph, D., 1996: The NCEP/NCAR 40-year reanalysis project. Bull. Amer. Meteor. Soc., 77, 437-471.

Kärcher, B., Peter, Th., Biermann, U. M., Schumann, U., 1996: The initial composition of jet condensation trails. J. Atmos. Sci., 53, 3066-3083.

Manabe, S., Strickler, R., 1964: Thermal equilibrium of the atmosphere with a convective adjustment. J. Atmos. Sci., 21, 361-385.

Mannstein, H., Meyer, R., Wendling, P., 1998: Operational detection of contrails from NOAA-AVHRR-data. Institut für Physik der Atmosphäre, Report No. 92, ISSN 09434771.

Miake-Lye, R. C., Martinez-Sanchez, M., Brown, R. C., Kolb, C. E., 1993: Plume and wake dynamics, mixing, and chemistry behind a high speed civil transport aircraft. J. Aircr., 30, 467-479.

Minnis, P., Ayers, J. K., Weaver, S. P., 1997: Surface-Based Observations of Contrail Occurence Frequency Over the U.S., April 1993-April 1994. NASA Reference Publication 1404.

Minnis, P., Young, D. F., Garber, D. P., Nguyen, L., Smith Jr., W. L., Palikonda, R., 1998: Transformation of contrails into cirrus during SUCCESS. Geophys. Res. Lett., 25, 1157-1160.

Newell, R. E., Zhu, Y., Browell, E. V., Ismail, S., Read, W. G., Waters, J. W., Kelly, K. K., Shaw, C. L., 1996: Upper tropospheric water vapor and cirrus: Comparison of DC-8 observations, preliminary UARS microwave limb sounder measurements and meteorological analyses. J. Geophys. Res., 101, 1931-1941.

Ovarlez, J., van Velthoven, P., 1997: Comparison of water vapour measurements with data retrieved from ECMWF analyses during the POLINAT experiment. J. Appl. Meteor., 36, 1329-1335.

Peixoto, J. P., Oort, A. H., 1996: The climatology of relative humidity in the atmosphere. J. Climate, 9, 3443-3463.

Peters, J. L., 1993: New techniques for contrail forecasting. Air Weather Service, Scott Air Force Base, Illinois. AWS/ TR-93/001, AD-A269686, 31 pp.
Ponater, M., Brinkop, S., Sausen, R., Schumann, U., 1996a: Simulating the global atmospheric response to aircraft water vapour emissions and contrails - a first approach using a GCM. Ann. Geophysicae, 14, 941-960.

Ponater, M., Brinkop, S., Sausen, R., Schumann, U., 1996b: Parametrization of contrails in a comprehensive climate model. Proc. International Colloquium on Impact of Aircraft Emissions upon the Atmosphere, Paris, 15-18 Oct. 1996, 373-378.

Read, W. G., Waters, J. W., Flower, D. A., Froidevaux, L., Jarnot, R. F., Hartmann, D. L., Harwood, R. S., Rood, R. B., 1995: Upper-tropospheric water vapor from UARS MLS. Bull. Amer. Meteor. Soc., 76, 2381-2389.

Roeckner, E., Arpe, K., Bengtsson, L., Christoph, M., Claussen, M., Dümenil, L., Esch, M., Giorgetta, M., Schlese, U., Schulzweida, U., 1996: The atmospheric general circulation model ECHAM-4: Model description and simulation of present-day climate. Max-Planck-Institut für Meteorologie, Report No. 218, Hamburg, ISSN 0937-1060, 90 pp.

Sassen, K., Dodd, G. C., 1989: Haze particle nucleation simulation in cirrus clouds and applications for numerical and lidar studies. J. Atmos. Sci., 46, 3005-3014.

Schmidt, E., 1941: Die Entstehung von Eisnebel aus den Auspuffgasen von Flugmotoren. Schriften der Deutschen Akademie der Luftfahrtforschung, Verlag R. Oldenbourg, München und Berlin, H. 44, 1-15.

Schmitt, A., Brunner, B., 1997: Emissions from aviation and their development over time. In: Schumann, U., Chlond, A., Ebel, A., Kärcher, B., Pak, H., Schlager, H., Schmitt, A., Wendling, P., (eds.) Pollutants from Air Traffic Results of Atmospheric Research 1992-1997. DLR Mitteilung 97-04, 37-52.

Schumann, U., 1996: On conditions for contrail formation from aircraft exhausts. Meteorol. Z., N.F., 5, 4-23.

Schumann, U., Wendling, P., 1990: Determination of contrails from satellite data and observational results. In: Schumann, U., (ed.) Air Traffic and the Environment. Heidelberg: Springer, pp. 138-153.

Soden, B. J., Fu, R., 1995: A satellite analysis of deep convection, upper-tropospheric humidity, and the greenhouse effect. J. Climate, 8, 2333-2351.

Soden, B. J., Lanzante, J. R., 1996: An assessment of satellite and radiosonde climatologies of upper-tropospheric water vapor. J. Climate, 9, 1235-1250.

Strauss, B., Meerkötter, R., Wissinger, B., Wendling, P., Hess, M., 1997: On the regional climatic impact of contrails: microphysical and radiative properties of contrails and natural cirrus clouds. Ann. Geophysicae, 15, 1457-1467.

Ström, J., Strauss, B., Anderson, T., Schröder, F., Heintzenberg, J., Wendling, P., 1997: In-situ observations of the microphysical properties of young cirrus clouds. J. Atmos. Sci., 54, 2542-2553.

Wang, P., Minnis, P., McCormick, M. P., Kent, G. S., Skeens, K. M., 1996: A 6-year climatology of cloud occurence frequency from Stratospheric Aerosol and Gas Experiment II observations (1985-1990). J. Geophys. Res., 101, 29407-29429. 
Warren, S. G., Hahn, C. J., London, J., Chervin, R. M., Jenne, R. L., 1986: Global Distribution of Total Cloud Cover and Cloud Type Amounts over Land. NCAR Technical Notes 273+STR.

Warren, S. G., Hahn, C. J., London, J., Chervin, R. M., Jenne, R. L., 1988: Global Distribution of Total Cloud Cover and Cloud Type Amounts over the Ocean. NCAR Technical Notes $317+$ STR.
Wylie, D. P., Menzel, W. P., Woolf, H. M., Strabala, K. I., 1994: Four years of global cirrus cloud statistics using HIRS. J. Climate, 7, 1972-1986.

Authors' address: Robert Sausen, Klaus Gierens, Michael Ponater and Ulrich Schumann, Institut für Physik der Atmosphäre, DLR Oberpfaffenhofen, D-82234 Weßling, Germany. (email: robert.sausen@dlr.de). 